\title{
FALLEN AGENTS: NEGOTIATIONS OF PATIENT AGENCY IN NORWEGIAN OPIOID SUBSTITUTION TREATMENT
}

\author{
ALEKSANDRA BARTOSZKO \\ VID SPECIALIZED UNIVERSITY, FACULTY OF SOCIAL STUDIES, OSLO, NORWAY
}

\begin{abstract}
Based on an ethnographic fieldwork, this article explores how patients in a Norwegian heroin-addiction treatment program negotiate their agency, navigating between policies, medical guidelines, and their own lived experiences as they seek what they perceive as appropriate medication. Outlining these patients' participation in treatment inside and outside the clinic, I illustrate that different types of agency are involved across these domains. I argue that patient agency is not something one has or does not have, but rather involves the institutional interpretations of these mobilised elements: What kind of agency is appropriate to exert in the Norwegian healthcare system? The analysis highlights the social constructions of the "addicted patient" and raises questions of the value of patient subjectivity and the politically tinged ascriptions of agency manifested in patient rights and guidelines for clinical decision-making.
\end{abstract}

Niniejszy artykuł, oparty na etnograficznych badaniach terenowych, ukazuje, w jaki sposób pacjenci objęci norweskim programem leczenia uzależnień od heroiny negocjują swoją sprawczość w staraniach o odpowiednie dla nich leki. Opisuję, jak pacjenci, nawigując między polityką, wskazaniami medycznymi oraz własnymi życiowymi doświadczeniami, aktywnie uczestniczą w leczeniu zarówno wewnątrz, jak i na zewnątrz kliniki. Przedstawiam, w jaki sposób w tych dwóch kontekstach aktualizowane są różne typy sprawczości. Argumentuję, że sprawczość nie jest czymś, co pacjent posiada bądź nie posiada; wiąże się ona raczej z interpretacją instytucjonalną, a więc tym, jakiego rodzaju sprawczość jest uznana za odpowiednią w norweskim systemie opieki zdrowotnej. Analiza kładzie nacisk na społeczne konstrukty „uzależnionego pacjenta" i stawia pytania o wartość jego podmiotowości oraz politycznie nacechowanych przedstawień sprawczości manifestowanych w prawach pacjenta i wytycznych dotyczących decyzji klinicznych.

Ke yw o rds: agency, addiction, noncompliance, opioid substitution treatment, patient involvement, Norway

\section{INTRODUCTION}

Agency, more specifically patient agency, is a central underlying element in the discourse of patient involvement that became a buzzword in national and global health strategies, plans and regulations of human services (Andreassen 2004, 20I6; Gubrium et al. 2016). During the last decade, politically tinged ascriptions of agency have figured 
centrally in debates about patient role in medical decision-making. Increasingly, international bodies and national health authorities have invited to break down the traditional paternalistic relation between patient and physician advocating patient-centered care as a vehicle to improve health care. For instance, World Health Organization drafted a major policy brief recognizing patient engagement as "a fundamental plank of health policy" (Coulter et al. 2008). Similarly, the United States' Institute of Medicine emphasizes "care that is respectful of and responsive to individual patient preferences, needs, and values and ensuring that patient values guide all clinical decisions" (200I, 6).

As the understanding of addiction as a disease has gained political attention, solutions and treatments have increasingly been defined through medical lenses. Consequently, the discourse of treatment and patient agency penetrated the field, shaping actors' subjectivities and expectations in new ways (Bartoszko 20I8b; 2018c). However, patients with substance addictions or dependencies ${ }^{1}$ face serious constrains when demanding participation in clinical decision-making. These demands evolve from clinico-political ideologies advocating for individual sovereignty and a model of patient involvement based on normative visions of responsibility and compliance. But a culturally constructed clinical image of the "addicted patient" as irresponsible, noncompliant, and ambiguous challenges that vision.

Based on a one-year-long ethnographic fieldwork among patients in opioid substitution treatment $(\mathrm{OST})^{2}$, this article asks: What kind of patient agency is appropriate to exert in the Norwegian health-care system? The article explores how patients receiving treatment for addiction negotiate their agency in such tense conditions, navigating

I Addiction is understood as an overwhelming involvement with any pursuit whatsoever (including but not limited to drugs or alcohol) that is harmful to the addicted person, to society, or both. Under this definition, opioid use "can take up every aspect of the addicted person's life - conscious, unconscious, intellectual, emotional, behavioral, social, and spiritual" (Alexander 2008, 35). On the other hand, dependency denotes non-overwhelming involvement with opioids, and persons who use opioids in this way are "dedicated to living stable, socially approved lives. Their drug use gives them pain relief, energy, or composure that they find indispensable for coping with the obstacles that they must face in their normal lives - although they must often endure harmful side effects" (Alexander 2008, 43).

2 Patients in OST are diagnosed with opioid dependence syndrome according to ICD-IO, which define the syndrome as "a cluster of physiological, behavioural, and cognitive phenomena in which the use of a substance or a class of substances takes on a much higher priority for a given individual than other behaviours that once had greater value. A central descriptive characteristic of the dependence syndrome is the desire (often strong, sometimes overpowering) to take psychoactive drugs (which may or may not have been medically prescribed), alcohol, or tobacco. There may be evidence that return to substance use after a period of abstinence leads to a more rapid reappearance of other features of the syndrome than occurs with nondependent individuals" (World Health Organization 1992). The ICD definition of dependence encompasses elements of both overwhelming (addiction) and non-overwhelming (dependence) engagements with substances ignoring the qualitatively essential difference between these two phenomena. 
between policies, medical guidelines, and their own lived experiences as they struggle for what they perceive as appropriate medication for their ailments.

I define patient agency as individuals' capacity to act to influence their treatment situations according to their will. These negotiations include all actions and behaviours concerning the treatment situation. Outlining patient participation in treatment inside and outside the clinic, I illustrate that different agentive elements are mobilised and resisted, and different types of agency are involved across these domains. Thus, patient agency is not something one has or does not have, but rather involves the interpretations of these mobilised elements.

\section{NARRATIVE AND NON-SOVEREIGN AGENCY}

In social sciences, notion of agency is employed in heterogeneous ways. In anthropological literature, it is used for two main reasons: to explain human creativity and to account for changes in social structure (Rapport and Overing 2000, 8-9). For instance, Leach (1977) saw agency as manifestation of criminality inherent in humans (Leach 1977, 19). He writes:

"All of us are criminals born by instinct. All creativity (...) contains within it a deep-rooted hostility to the system as it is" (Leach 1977, I9).

Human action, in other words, is driven by a desire to challenge established societal rules simultaneously producing new ones. In the same vein, Lavie, Narayan, and Rosaldo define creativity as "human activities that transform existing cultural practices in a manner that a community or certain of its members find of value" (1993, 5). I follow this strand of thinking in my approach to agency drawing further on Lucas' (2017) concept of narrative and non-sovereign agency.

The premise for my use of agency in this article is this: As individuals, we enter social situations equipped with the culturally shaped ideas of possible lives in a given social context at a given time, and we are constantly in quest for creating our future and living out multiple possible futures (Bruner 2004; Mattingly 2009). Therefore, people are meaningful agents who are both constituted by a complex matrix of stories and have any number of stories of their own to tell and enact (Lucas 20I7; Mattingly 2009). According to Lucas:

"Often we are blinded to the agency of others by an assumption that agency is equivalent to perfect freedom of choice or to the absence of coercion. We are prone to see people, as Hutchings (20I3) puts it, as "choosers or losers" rather than as consistently beset both by the capacity to act and a number of factors that compromise this capacity (...) And each of us, though certainly some much more than others, is subjected to harmfully reductive narratives. [Yet,] everyone is both embroiled in inescapable power relations and capable of moments of recognition" (Lucas 20I6, IO, I2). 
Inspired by feminist theory, Lucas is interested in

"uncoupling the notions of agency and autonomy to defend a definition of agency that is resilient in the face of coercion, oppression, and systematic marginalization" (Lucas 2016, I2).

Her perspective accounts for structural inequalities and injustice, but does not frame these as invincible obstacles to agency. Following Lucas's (2017, I2) suggestion, I dispense with the idea that we are either free or unfree, either agents or victims, either "choosers or losers" so as to challenge the tendency to think of patients or "drug addicts" as passive victims of biopower or coercion, and of biomedical professionals or law enforcements agents as self-legislating, wholly autonomous individuals. This approach acknowledges all human beings as "agents capable of unpredictable action" (Lucas 2016, 13), instead of defining them according to received social categories and dominate narratives.

Agency, therefore, is a relational and interactional concept, rather than an innate or transcendent capacity which the self-governing subject may exercise. It is

"the capacity to appear to another within a plurality of subjects and selves, each of whom is constituted by shared norms and narratives" (Lucas 2017, 28).

Resting on this kind of inter-subjectivity, the narrative concept of agency can provide a strong sense of uniqueness, individual freedom, and meaningfulness. Therefore, I define agency as the capacity to make sense, to meaningfully act (Lucas 20I7).

\section{OPIOID SUBSTITUTION TREATMENT IN NORWAY}

In Norway, a country of 5.3 million inhabitants, approximately 8,700 and I2,700 persons are estimated to be injecting drug users (predominantly heroin) (BrettevilleJensen and Amundsen 2009; Amundsen and Bretteville-Jensen 2010). In the past, users of illicit drugs could be divided into subcultures based on their drugs of choice. Lately, however, the prevalence of poly-drug use has evinced a rise. Combinations of opioids (heroin, methadone, buprenorphine, morphine and other morphine-like substances) and benzodiazepines are most common. Amphetamine and other central nervous system stimulants are widely used in combination with opioids. Norway has 300 fatal overdoses annually (European Monitoring Centre for Drugs and Drug Addiction, 2017), a fairly consistent number over the last decade. To address this challenge, the national OST program existing since 1998, has relaxed its admission criteria and introduced new medications. At the end of 2017, 7,622 patients were in Opioid Substitution Treatment (OST). The average age of these patients was 44.9 years and approximately $70 \%$ were men (Waal, Bussesund, Clausen, Lillevold, \& Skeie, 2018). 
In OST, patients with heroin addiction receive long-lasting opioid substitutes for usually illegal - heroin under controlled conditions. The substitution medications, such as methadone or buprenorphine, are said to eliminate heroin withdrawal symptoms, reduce cravings, and block the effect of heroin. Treatment of opioid addiction with substitution medication has shown an increased patient survival rate, along with a diminution in health damage, criminal behaviour, and somatic diseases, compared with psychosocial treatment alone (Hedrich et al. 20I2; Riksheim et al. 20I4; Skeie et al. 20II).

According to the national guidelines for OST, the aim of substitution treatment is:

"to improve [patients'] life quality and to assist them in altering their life situation by improving their optimal coping and functional levels. The objective is also to reduce the harmful effects of opioid addiction and the risk of death from overdose" (Helsedirektoratet 20IO, 3).

The OST program encompasses social service centres, general practitioners, and specialised healthcare. The treatment is mainly outpatient, with medication supplied free of charge at the local pharmacy or through the OST centre. The OST system aims at a rather high degree of control. Medication must be taken under daily supervision until patients are determined to have stabilised and gained sufficient control over their drug use, as measured through urine samples indicating no evidence of non-prescribed drugs. Once patients stabilise, they may be allowed to self-administer medication at home. Medication lasting for up to a week or more, depending on preapproved travel plans, may be available.

The guidelines recommend three medications for treatment: methadone, highdose buprenorphine (Subutex), and a buprenorphine-naloxone (Suboxone), with buprenorphine the recommended first choice. However, the guidelines emphasise that "patient's preference should be emphasised in the choice of medication" (Helsedirektoratet 20I0, 5I-52).

Patients respond differently to prescribed medications. Some are satisfied, while some experience disabling side effects, persistent cravings, or just do not feel well. Switching treatment modality requires negotiations between the patient and the OST program, and these negotiations are the context for this study. I focused on choice of medications because it is the most contentious issue in debates on patient involvement in OST and illustrates the power asymmetries in the clinical setting while casting new light on patient agency.

\section{SUBSTANCE TREATMENT REFORM AND LEGAL PATIENTISATION}

In 2004, Norwegian authorities extended public goods, such as better health provision and rule of law, to groups previously excluded from these benefits, such as OST patients. Incorporating OST patients into the "ordinary" patient community was 
a form of inclusion and a recognition of their agency. This inclusion was to be achieved through Substance Treatment Reform, formal medicalisation of addiction, and an increasing use of legal structures to assign treatment. Responsibility for treatment was shifted from social welfare services to the healthcare system, with addiction treatment redefined as a specialised health service along the lines of somatic and psychiatric care. The reform guaranteed OST patients access to specialised healthcare and established patients' rights to safeguard this goal.

Patients' rights were central for my interlocutors' understanding of their new position in the clinical landscape, which changed their expectations for involvement in treatment. Following the global rise of ideologies advocating active patient engagement, Norwegian health authorities have ascribed increased significance to patients' experiential knowledge, formalising it through treatment protocols and legal documents. For instance, the Norwegian Patients' Rights Act states:

"The patient is entitled to participate in the selection of available and prudent examination and treatment methods. The service offer should be as far as possible designed in cooperation with the patient and $[\ldots]$ patient's opinion should be strongly considered" $\left(\$_{3-I}\right)$.

Thus, as I read the expression "as far as possible", this act extends agency to patients. The question is not whether patients should have agency, but what kind and on what premises. The act offers a space for multiple legal and clinical definitions, and thus, for negotiations and normative judgments. Norwegian law and the literature do not clearly define patient involvement, but they chart a clear image of a desired patient: one who is active, autonomous, competent, and responsible. Therefore, clinicians and patients must strike a balance between two main policy documents: the Patients' Rights Act that regulates patients' involvement in choice of treatment modalities and recognises patient agency and individual needs, and the OST guidelines that focus on control and express "cautiousness" regarding patients' agency. Thus, OST treatment is built on a tension between the responsible subject assumed in patients' rights discourse and the irresponsible drug user assumed in OST program's disciplinary practice.

\section{METHOD}

My overall objective during fieldwork was to explore the experiences of OST patients in the context of the Substance Treatment Reform of 2004, which granted patients' rights to persons diagnosed with dependence. Increasingly, I focused particularly on patients' experiences of changes in treatment modalities that appeared to be contentious. Patients who wished to switch or keep their prescribed drugs had to negotiate with the OST interdisciplinary treatment team, usually represented by 
social workers. Some OST patients chose to take legal action, filing a complaint with the County Medical Officer. The length and intensity of this process varied depending on the patient's situation, preferences, negotiating capital, and relationship to the treatment team, as well as the prescribing physician's preferences.

I followed closely six patients who wished to switch or keep their medication during a I-yearlong (2013-20I4) ethnographic fieldwork in several Norwegian municipalities. OST patients are a heterogeneous group of persons: those leading very "stable," mainstream lives; those actively engaged in open drug scenes; and those in between these two extremes. The interlocutors who participated in my study belonged to all categories, fluctuating among them, as I will show. They all used different combinations of medications depending on their situation and geographical location. They were recruited through a traditional snowballing method beginning with my initial contact with an OST patient recruited through a personal network. Participation in the study was based on an informed consent procedure approved by the Norwegian Centre for Research Data. The Regional Committees for Medical and Health Research Ethics evaluated the project and found no reason to apply the additional regulations that are specific to medical and health research.

Participant observation was a key fieldwork component. Among other things, I accompanied the patients during OST consultations, prehospitalization meetings, and meetings with their treatment teams, lawyers, or patient associations. I also followed them through their everyday OST activities such as visits to pharmacies, lowthreshold health clinics, detoxification units, and urine collection sites. While the most intensive relationships were developed with these six patients, I also met their friends, friends of friends, and other OST patients, who shared their stories. Many of them were satisfied with their treatment.

Altogether, I collected around 40 treatment stories. In addition, I participated in relevant events such as patient gatherings, workshops, local professional addiction conferences, seminars, and courses, which yielded insight into the main narratives and rationales in the field. I also conducted over 60 in-depth interviews with representatives of patient organizations, addiction researchers, OST physicians, OST consultants, social workers, general practitioners, health bureaucrats, the patient ombudsman, and lawyers.

Ethnographic field notes and transcripts from interviews and documents (e.g., health records, OST guidelines, and white papers) were coded and analyzed for key empirical themes emerging from the material. These themes were further analyzed against key words from policy documents, clinical guidelines, and bills of rights (such as "individualized treatment," "patient involvement," "patient agency" and "quality of life"), and for how these ideological and political intentions corresponded to the ideas and experiences of patients and clinicians in treatment practices. 


\section{PATIENTS’ SUBJECTIVE AGENCY}

Barrows and Pickell formulate the aim of treatment recommendations as:

“changing a patient's existing unacceptable situation into a preferred one [such as] a cure, a relief of pain, an improvement in health status, a prevention of impending illness or complication, or a reduction of distress or concern, depending upon the patient's and [the clinician's] objectives" (Barrows and Pickell I991, I63).

Already at this point, the negotiations of patient agency are explicit: What is the goal of OST and according to whom? Is the goal to stop heroin use entirely or to reduce it? Is it to enable the patient to work or study? Is it to eliminate the patient's "highs" or to allow the patient to feel "highs" on a legal or safer medication? Is it to avoid overdoses and possible death or to enable the patient to live better despite risks? Patients and clinicians often disagree on these desired outcomes as policies of harm reduction and goals of abstinence clash. Patients who prefer a shorter life span challenge the clinical imperative to prolong life (Bartoszko 2018a). Ideas of a good life including "highs" contrast with the ideal of living in non-altered ways (Bartoszko 20I8b). The plethora of patients' subjectivities, past experiences, and dreams for the future challenge the vague goal of OST to "improve life quality". Disagreements concerning these goals result in treatment recommendations that often override patients' wishes and disregard their personal, social, and clinical experiences.

As a creative capacity, agency can be engaged to influence the state of the world. Here, as Fischer pointed out, "the importance of realised effectiveness is unclear: exerting power so as to influence the world does not necessarily mean that the world is so influenced and changed" (Fischer 2014, I52). In this respect, Fischer coined a term subjective agency, referring to the individual's internal ability to make choices and control procedures (Fischer 2014, 153).

Studies document that patients experience diminished subjective agency in OST, which is described as a hostile system, fostering suspicion and distrust, while reproducing social stigma and exclusion (Bartoszko 2018a; 2018b; Bourgois 2000; Friedman and Alicea 200I; Harris 20I5). Other scholars emphasise OST's capacity to monitor and control patients' bodies requiring them to forgo pleasure (Moore 2008) by consuming medications that stabilise withdrawal symptoms yet may not bring patients the desired effect or a better quality of life (Bartoszko 2018a).

My interlocutors experienced an inability to influence their situations and felt discredited and disrespected. They feared sharing their real stories, such as relapses, with their treatment teams because of the restrictive consequences. Patients reported an "bureaucratic indifference" (Herzfeld 1992, I) among clinicians who treated them as cases, not individuals. For instance, they experienced degraded agency when clinicians imposed urine testing rather than simply asking them to report any drug use. Clinicians 
tended to rely on testing because of underlying mistrust of patients and time constraints that limit opportunities for constructive dialogue with patients. A conversation with Oscar, a 40-year-old patient, illustrated this experience:

"[Oscar:] They say they look at us as humans. Talking so much about psychiatry, change of mindset; that they take us seriously and with respect. But when you get in there [OST] it's just: 'What have you taken? How much? When?'

[Aleksandra:] But isn't it important ...?

[Oscar:] Well, yes. This too. But nobody asks how I am. Or no, do you remember the social worker lady. Sweet and kind. She asked, but now it's that with the youngsters. They have no clue. And then it is just like, 'Hello, how are you?' And you're not waiting for answers. Like for real answers. (...) So all the meetings, they are so technical, it becomes so technical. So little of all the mental and social they are talking about".

In such cases, patients experience an imbalance between what they provide (bodily fluids and answers to uncomfortable questions) and what they receive (the desire to be "really heard and seen"). The imbalance is disempowering and leaves patients stripped not only of subjective agency but also of the possibility of getting well. As a result, individuals' agency as patients with needs and right to talk, share, and be involved is undermined.

At the same time, patients are very cautious of what they say during their consultations. As 50-year-old Ina expressed:

\footnotetext{
"The main focus $[\ldots]$ can quickly be directed toward something that patients can't really say anything about, such as consumption of [non-prescribed] drugs. Because it would lead to restriction of personal freedom and desires. Well, then you have to lie. And then OST understands that you are lying, so you have to lie more and so on. The worst here is that those who work in OST don't stop this. God, so much waste of time and energy".
}

This example highlights relational nature of agency. On the one hand, patients experience diminished agency because they have to hide their "true stories", fearing consequences of their "confessions", as patients often call these consultations. On the other, lying as an attempt to deceive (Barnes 1994) in order to achieve goals within limited conditions is a way of exercising agency and a means of control.

\section{AGENTIVE DISABILITY AND AMBIVALENT AGENCIES}

Every treatment is initiated by a set of negotiations, negotiations of roles, of symptom management, of knowledge, meanings, and life forms (Strauss et al. 1963; Kleinman 1980). Studies suggest that patients can easily be swayed by physician authority when choosing treatment options, and that patients are willing to follow physicians' recommendations even if they are contrary to their own wishes (Gurmankin et al. 2002; Karnieli-Miller and Eisikovits 2009). In OST, the situation is often the opposite, and 
physicians struggle to maintain authority. As most OST patients are experts in "lay pharmacology" (Webster et al. 2009), the clinical negotiations may be more explicit and, often, dramatic. The vast majority of OST patients enter the clinic with specific ideas about their treatment, in particular, their preferred medication. My interlocutors argued that they knew which medication worked best for them and attempted to get OST professionals to acknowledge that experiential knowledge. In other words, they demonstrated patient agency by requesting specific services or by responding to given recommendations (Gill 2005; Koenig 20II).

Often patients' requests went against the doctors' opinions, such as: "No, I don't want Subutex because it gives me anxieties" or "I think morphine would be a better option to keep me healthy". In response to the prescriber's biopower, patients wield counter power, the strength of which lies in their pharmacological reasoning based on lived experiences unavailable to clinicians. At stake here is not the recommendation itself, but what it reveals about power relations in the clinic, about the social treatment of patient agency when medical knowledge is questioned, and about the social and clinical understanding of addiction and pharmaceutical enhancement of life quality.

Patients understand patient agency as the ability to take effective action to get what they want, but clinicians and health bureaucrats see limitations to this understanding for two reasons: first, institutional constraints often hinder fulfilment of patients' requests, and second, clinicians and health bureaucrats tend to ascribe to these patients what I term agentive disability, a diminished capacity to take the rational action that would comply with the institutional imaginaries of a competent patient. When patients express their wishes for particular medications, clinicians often attribute this kind of agency to their treated condition - addiction - and thus distinguish between desired and problematic agency. One prescriber described the challenge of differing views of agency:

" $[\mathrm{H}]$ ealthcare professionals become quite uncomfortable with a situation in which they see that the patient is very well informed. Especially when you have, perhaps, very tight rules binding you so that you can see that what the patient says makes quite a bit of sense. Yet I have to adhere to these rules. Then you can see that the doctor comes to a point where he has to, kind of, defend a reality with which he doesn't necessarily agree completely. [...] Nevertheless, the fact is that there is an elephant in the room, which doesn't make things easy to discuss. This is because it sometimes implies discrediting the patient's motives. [...] By saying that... OK, when you say that you now want heroin as a substitute medication or something else, then I know that one of the problems is that it is a drug (rusmiddel). I don't want to contribute to your intoxication (rusing). This is often difficult to talk about, because it could mean suspecting the patient, I think. [I]n some cases, we don't agree and it is me who gets to decide. But then it is important that we keep people in treatment. There is such a dilemma regarding what we can accept without perceiving it as unsound and what the patient accepts".

During discussions of the choice of modality in OST, patients' experiences and in-depth knowledge of pharmaceuticals are often their weakness. The idea of involving them in treatment becomes a dilemma, and therefore, the formulation "patient's 
wish" (ønske) in OST guidelines may be a slightly unfortunate way of mirroring the patients' competence and involvement. During my fieldwork, clinicians tended to interpret the "wish/preference" in various ways, and these terms often bore normatively negative associations. I could spot this through the context in which they frequently used the words wish or preference: "[Patients] prefer [morphine] because they can get high"; "Some [of the patients] have their, you know, preferences"; or "We can't give [into] their wishes". With these statements, practitioners questioned patients' motives and interests. Clinicians dismissed patients' experiential knowledge, aligning it with value-laden images of the addicted patient having distorted agency, which the disease model of addiction and neuroscience strongly promotes (e.g. Hyman 2005). Because the line between the preferred effect of OST medications and so-called "drug seeking behaviour" is indistinct, the clinical appreciation of patient agency is tested.

\section{OPPORTUNITIES STRUCTURES AND "FRUSTRATED FREEDOM"}

Agency is not a totally free choice, and neither are patients free to choose whatever treatment they wish. Choice is conditioned by local clinical cultures, legal regulations, and available and authorised research at a given time and expressed in treatment protocols (e.g. Bartoszko 2018b, Gjersing et al. 20II). For instance, 53-year-old Siv was in treatment with morphine for three years, with good results according to OST, and she did not want to switch to Suboxone, which the new guidelines recommended. She filed complaints to avoid the compulsory conversion. Before her final and successful complaint to the Norwegian Board of Health Supervision, the following dialogue took place between her and the physicians during a pre-hospitalisation consultation:

\footnotetext{
" [Detox physician:] You feel that you are pressurised, but it seems that [OST does] not have a choice because of the guidelines and regulations and all of this... [...].

[OST physician:] At the same time, it is not wrong to have this feeling, to be pressed for something you don't want...

[Siv:] Yes, this is a duress situation.

[OST physician:] Now, we have tried all the instances... they have written that it appears you can't appeal any more. This is tough for you, no doubt about it.

[Detox physician:] The situation is pretty much set in concrete. As long as you live in this country, the case is closed. So everything is already decided [...].

[OST physician:] We have no authority. We are as stuck as you are".
}

In this meeting, the clinicians spoke with many voices. We hear an authoritarian voice that patient experienced as disempowering. There are "higher authorities that decide". At the same time, the clinicians acknowledged the patient's perspective, but expressed their own powerlessness. With treatment protocols restricting their clinical responsibilities, they expressed hopelessness regarding these constraints and the patient's fears. 
In their descriptions of patient cases, clinicians emphasised institutional hindrances that limited their ability to consider the individual's situation. A physician shared her thoughts on compulsory conversion of OST patients to Suboxone, which was introduced to the program to prevent injections and diversion to illegal markets:

\begin{abstract}
"Well, it makes a difference if you are in charge in the Directorate of Health or the government, or if you are a legislator. Then you are able to say that there are so many people who die of this drug and that one. We have now seen that more people die from buprenorphine as well. Overdoses. We have to do something about this. Everyone needs to get on to Suboxone, which is less dangerous'. That, in a way, becomes the perspective when you carry the systemic view with a sense of responsibility for a third person. But then you also have this one-on-one relation between the clinician and patient, which is a slightly different setting. Unfortunately, this is a dilemma. Sometimes, in order to achieve something at the system level it has to be harder for some patients and a little more difficult for some single patients. For instance, [it requires] taking a medication that they may not have required in the first place".
\end{abstract}

Precautions are made in the clinic because of the medications' risk profiles and patients' assumed unpredictable conditions; however, the precautionary practices limit patients' subjective agency as patients are not even given the chance to "prove that they are not guilty" of selling, injecting, or abusing the drug. Patients tend to express their experiences as individual and personal problems to be appreciated, but these often conflict with institutional and political needs and obligations.

Exposed to the clinico-legal promises of "involvement", patients expect satisfaction. In the above situation, Siv left the meeting disillusioned and frustrated. Meetings in which patients' preferences are suspected and dismissed because of treatment protocols dash patients' expectations of being active participants in treatment, triggered by the new law. According to Fischer,

"The effectiveness of aspiration and agency is often limited by available opportunities structure [...]. The will is important, but there also has to be a way" (Fischer 20I4, 6).

Opportunities structures encompass formal and informal social norms; class, gender and other systematic distinctions; and legal regulations, treatment protocols, and other institutional factors that define what is possible. Individual agency acts on choices, but those choices are structured through socio-political processes that transcend the individual. When subjective agency far exceeds available resources and opportunities, we find "frustrated freedom". This kind of freedom permeated my interlocutors' experience with OST. As Fischer wrote:

"Individual[s] [may] possess the subjective agency to achieve more than their material resources and opportunity structure can enable. In such a condition, opportunity and resource deficits frustrate their perceived capacity to successfully make the decisions and choices that they believe would enhance their well-being" (Fischer 2014, 156). 


\section{Resistance outside the clinic}

So far, I have shown that patient agency, in its narrow sense, can be troublesome in the landscape of diverging policies, guidelines, and lived experiences; and as a result, patients experience clinical disempowerment. Yet, actively negotiating their treatment, patients appear as creative and resourceful social agents, exercising more agency than is typically assumed.

I now focus on how patients enact and negotiate their agency as they exert the right to refuse the recommended OST modality and to engage in various life strategies outside the clinic. Through their non-acceptance, understood as a form of active resistance (Stivers 2005, 52), patients actively participate in clinical decisions and create the opportunity to shape treatment and future outcomes.

\section{Legal action}

Before participating in yet another consultation, Siv said to me: "If it doesn't work here [in the clinic], let's try elsewhere". She was prepared for OST to reject her desire to keep her preferred medication, and planned to file a complaint with the Norwegian Board of Health Supervision. The Substance Treatment Reform granted patients the right to complain, and those with sufficient capital use the law to change the course of their treatment (Bartoszko, 20I8c). Thus, patients' agentive space has expanded beyond the clinical setting as the law provides another new pathway in a contentious landscape.

Anthropological accounts of biological citizenship (Petryna 2002) emphasise that patients' agency elicits changes not only to medical classifications, but also to the ways in which claims are made on the state. In the field of addiction, too, I argue, increased intersections between medicine and the law have created new subjects that threaten clinical authority in new ways. Patients' rights may serve to enable patient agency, which has been diminished in the clinic, and thus shape, to paraphrase Hacking (1985), a new kind of patient - the patient-citizen - who, not only seek specific medical treatment, but also fulfilment of their rights. The Substance Treatment Reform mobilised legal consciousness among former "drug addicts" who are now patients with a diagnosis (Bartoszko, 2018c), giving them a novel opportunity to make meaningful decisions about compliance. Under the treatment reform, a central feature of patient agency is to challenge potential medical wrongs, thus empowering disadvantaged patients, but also laying the foundation for further corrosion of medical authority. The following situation illustrates this situation.

One of the OST program reports about Siv's long legal process notes:

"The patient was very much focused on rights in her statement and there was much talk about laws and rules, and, unfortunately, little room to assess her health condition".

Yet, each time the patient asked for an individual health evaluation, she was referred to guidelines that were treated as "law-like". During the consultations, no one 
thoroughly evaluated Siv's situation, an omission that the Norwegian Board of Health Supervision noticed and documented. This example of OST's structural ambiguity (Best 2008, 356) highlights the ironic and confounding character of bureaucracies (Hoag 20II, 8I). Expectations towards patients as active agents are blurred, and although patients are expected to turn to the law, such engagement can be viewed as a burden to the clinic (Bartoszko, 20I8c). As patients enter the realm of powerful bureaucracies, they engender a potent force of clinicians, illustrating the disaggregated character of power and of the state. In Siv's situation, the clinicians appeared "petty empowered... the dominated segment of the dominant" (Marcus 2000, 3). They were complicit with the powerful institution of law, yet antagonistic to it when it disturbed the established patient-clinician dynamics. In this context, patient agency expressed through legal mobilisation threatened medical authority, generated fragmented governance, and thus initiated possibilities for patients but also potential conflict in the clinical relation.

\section{Precarious agents}

During my fieldwork, patients who wanted to switch from buprenorphine products to methadone or from methadone liquid to methadone pills had a difficult time. Pending OST decisions, they employed various strategies to deal with their situations. Patients who were dissatisfied with a treatment regime often engaged in "non-adherent practices" which the clinical narrative discourages. In addition to experiencing diminished subjective agency, patients often felt that OST acted against their interests. In an attempt to reclaim self-control and self-regulation, patients devised strategies of resistance toward the system, such as diversion, unsupervised weaning, self-prescribed split dosing, or cheating with urine samples (Bartoszko 2018a). To curb side effects and achieve a better quality of life, some of my interlocutors manipulated the system or supplemented their medications. The following examples illustrate this behaviour.

\section{Jon}

Jon had been with the OST for I3 years. Six years ago, he began experiencing harsh side effects of the methadone liquid he had been consuming since he started treatment, including stomach and intestinal spasms, nausea, and severe vomiting. He asked to switch to pills, which he tolerated much better. OST refused his request using the diversion argument, citing the guidelines. They wrote in their response to Jon's application,

"According to the guidelines, 'methadone may be given in a form other than liquid mixture only in exceptional cases and in terms of sufficient control of [patient's] drug habits'”.

Jon filed a complaint with the County Medical Officer. Pending a decision, he continued to use the liquid mixture, until he felt too sick to ingest the medication and injected it, exposing himself to medical and social risks. In addition, he used cannabis to curb nausea and exchanged the liquid methadone with tablets on the black 
market. His "pill days" gave him some relief from the disturbing side effects and time to recharge his energy to continue his fight.

Jon's situation not only caused him to doubt OST's concern, but also hindered his social rehabilitation and challenged his identity. He wavered between a new "rehabilitated life" that he had sought when he joined OST and his old "junkie life". To cope with the unsatisfying medication, he continued to visit the illicit drug environment in town to make exchange arrangements, opening himself to suspicion and fulfilling OST's low expectations of him. In addition, he was challenged to restrain from using other drugs during these visits, and his use of cannabis made it difficult to prove to OST that he was "reliable" and "stable" enough to get methadone tablets on a weekly basis (according to OST, only stable patients were permitted to get methadone tablets).

\section{Oscar}

I accompanied Oscar to a downtown pharmacy where he picked up his I2 mg of Subutex every Wednesday. Back at his place, I saw him take Io mg of his dose and hide the rest in a box under his bed. I questioned why he did not the entire dose.

"[Oscar:] Well, I am trying to taper off. If I tell them [OST] that I went down, they will give me just Io...

[Aleksandra:] That's fair, I suppose, isn't it?

[Oscar:] Well, no. Because if someday I feel that I need more [Subutex], they will not give me any.

[Aleksandra:] Like if you have a bad day and cravings and stuff, you cannot call them and get a bit extra?

[Oscar:] Nope.

[Aleksandra:] That's why you keep some away for a rainy day?

[Oscar:] Yep".

OST deems such stockpiling as irresponsible. First, it contributes to a larger cache of "OST medications floating on the streets", and the media has repeatedly reported theft in the rehabilitation centres where Oscar lived. Second, unsupervised weaning and "tinkering" with strong medications involves medical risks (Helsedirektoratet 20IO). Yet, as Oscar's story illustrates, OST patients live in an uncertain system that is not geared for "emergencies" or to facilitate rehabilitation. Rather, the system is geared to maximise crises, spare some quantities of medication, and risk theft or sale.

Based on these stories, I argue that the OST system is built on technologies of suspicion and is neither designed nor organised to facilitate rehabilitation of thought, thus leading to clinically disapproved actions. The various creative ways in which patients deal with mistrust while coping with precarious treatment situations serve to maintain harmful, unwanted behavioural patterns. The control measures lead to patients' engaging in risky behaviours including hazardous administration, poly-drug use, and 
illegal tapering of prescribed medication (see also Bartoszko 2018a; Dahl 2007; Harris and Rhodes 20I3; Mjåland 2015).

The precarious treatment left my interlocutors to circulate between worlds, identities, and possibilities, neither patients nor addicts and without genuine agency in the dominant discourse of patient involvement.

\section{COMPLIANCE AS IDEOLOGY THREATING PATIENT AGENCY}

Trostle (1988) argued that compliance should be regarded as an ideology supporting the authority of medical professionals, rather than the only right therapeutic route. Yet, he noted, the assumption is that in exchange for a physician's services, a patient owes fees, cooperation, and compliance; noncompliance is usually the patient's fault (Trostle 1988, 305). Clinicians interpreted Jon's and Oscar's actions accordingly. As these two manipulated the system to cope with unsatisfying treatment, they fulfilled the OST clinicians' pre-existent perceptions of OST participants as noncompliant, irresponsible, and ambivalent patients. In addition, their noncompliance was seen as lack of self-control which clinicians attributed to the "addict's" distorted agency stemming from a compulsive desire to use and "a force other than his own". Indeed, clinically, addiction is characterised by a loss of control over drug use despite negative consequences. This characterisation frames addiction as a condition in which the capacity for autonomous agency, control, and decision-making is completely undermined. Kirmayer (1992) pointed to the narrative misreading in clinical situations in which patients do not seem to accept clinical reasoning which can lead to their being categorised as noncompliant. He wrote,

"When this sort of education fails to change the patient's behaviour - even though the patient can recite the biomedical facts and seems to understand the doctor's line of reasoning - the physician suspects some hidden perversity of the patient's mind" (Kirmayer 1992, 326).

I found this kind of misreading common in the clinical and social imaginaries about noncompliant OST patients.

However, some forms of noncompliance are inherently rational and logical (Conrad 1985; Fainzang 2014; Trostle 1988). Indeed, my study documents that

"what appears to be noncompliance from a medical perspective may actually be a form of asserting control over one's disorder" (Conrad 1985, 29).

The way patients acted were examples of asserting control over one's clinical and social situation, a tactical agency. Tactical agency refers here to how patients "cope with the concrete and immediate conditions of their lives" (Honwana 2005, 49). However, 
patients' actions come from a position of disempowerment. Thus, tactical agency, as "an agency of the weak", includes vulnerability and an ability to cope. The way Jon and Oscar administered their prescribed and illicit drugs was as an active engagement of patient agency within the given conditions and with available resources.

\section{GOOD AND APPROPRIATE AGENCY?}

The provided examples highlight that the agentive nature can be ambiguous. I use Durham's term "ambiguous agency" (2000, II6) to refer to examples of agency that contrast starkly with established, normative ideas about autonomy, responsibility, and the kind of behaviour patients should demonstrate, the activities they should engage in, and the spaces and places they should inhabit.

If patients' agency is considered negative, challenging, and problematic, then clinicians more likely question it and attempt to curtail it. Institutional constraints become more significant and explicit when resistance is present. Such negative agency has to be overcome through modes of disciplinary control or precautionary practices designed to bend patients' conduct towards morally and socially approved goals, transforming social agency into "responsible agency". On this issue, Hoggett remarked:

"[T]here is a danger that we [...] slip into equating agency with constructive coping, as if the two were synonymous. The point is that there is nothing necessarily constructive about agency and we should beware of smuggling normative assumptions into our thinking here, as if agency is good and absence of agency is bad" (Hoggett 200I, 42-43).

Patients' resistance reveals the contradictions between the sociological notion of agency and that promoted by policies and the practical field of medicine. The notion of agency as something inherently positive fails when we deal with actions that go "against the grain", that have goals inconsistent with political ideals of freedom, the principles of "universal reason", or "self-interest" (Mahmood 200I); in other words, that counter normative assumptions about the reasonable patient.

My fieldwork reveals precisely how, in the practice of medical interventions, the agency of "out-of-place" patients is often considered inappropriate, and may be identified as an obstacle to the clinical intervention itself. OST patients are allowed - moreover, they are praised - for being "agents", but their agency must be of the "right" kind. In other words, the negotiation of patient agency in OST is not about agency being acknowledged, but rather about what kind of agency is deemed appropriate. 


\section{CONCLUSION}

This article calls into question ideologies promoting "patient involvement" and "individual treatment" when the daily practice of clinicians requires a more pragmatic, tacit kind of thinking that accounts for structural conditions and patients' perceived ambivalence. My investigation of patient agency inside and outside the clinic shows that policies, treatment protocols, and legal regulations may serve as both "thinners" and "thickeners" of patients' agency (Klocker 2007) by constraining and expanding patients' range of viable choices.

Although the OST system can leave patients feeling trapped and powerless, they are not passive or docile in their dealings with OST and the health-care bureaucracy. They demonstrate the ability to influence events in their social worlds, which emphasises that clinicians do not necessarily hold all the power in social relations. Patients' actions, although illustrating the "agency of the weak", testify to the decreasing status of the physician and the erosion of medical authority.

Patients and clinicians find their own paths between policies, treatment protocols, and patients' lived experiences. Tracing these, they negotiate the narrow form of "patient agency" and shape new and broader forms. In other words, patient agencies are made and cannot be assumed in clinical reality. Their form, role, and significance change according to opportunities structures and how individuals engage with them. Thus, agency is not something a patient has, but rather a cascading series of contingent actions a patient does, as a temporally embedded process of social engagement informed by the past but oriented toward the present and the future.

\section{BIBLIOGRAPHY}

A l ex a n d e r B. K. 2008. The globalization of addiction: a study in poverty of the spirit. Oxford.

Amundsen E.J. and Bretteville-Jensen A. L. 20IO. Hard drug use in Norway. Nordisk Alkohol- \& Narkotikatidskrift 27 (I), 87-94.

A nd re a s s en T.A. 2004. Brukermedvirkning, politikk og velferdsstat. Oslo.

Andre as sen T. A. 20I6. Professional Intervention from a Service User Perspective. In J. F. Gubrium, T. A. Andreassen and P. Solvang (eds.), Reimagining the human service relationship. New York, 35-56.

$\mathrm{B}$ a r n e s J.A. 1994. A pack of lies: towards a sociology of lying. Cambridge.

B a r rows H.S. and Pi ckell G. C. I991. Developing clinical problem-solving skills: a guide to more effective diagnosis and treatment. New York.

B a r to s z o A. 20I8a. The lethal burden of survival: making new subjects at risk and the paradoxes of opioid substitution treatment in Norway. Contemporary Drug Problems 45 (3), 208-226.

B a r to s z o A. 20I8b. The pharmaceutical other. Negotiating drugs, rights, and lives in substitution treatment of heroin addiction in Norway. Oslo. 
B a r t o s z o A. $2018 \mathrm{c}$. From hope to $\$_{3}-\mathrm{I}$ : legal selves and imaginaries in the wake of substance treatment reform in Norway. Journal of Legal Anthropology 2 (I), I-25.

B est J. 2008. Ambiguity, uncertainty, and risk: rethinking indeterminacy I. International Political Sociology 2 (4), 355-374.

B o u r g o is P. 2000. Disciplining addictions: The bio-politics of methadone and heroin in the United States. Culture, Medicine and Psychiatry 24 (2), I65-195.

Bretteville-Jensen A. and Amundsen J.E. 2009. Forbruk av heroin i Norge. SIRUS Rapport. Oslo.

B r u n e r J. 2004. Life as narrative. Social Research 7I (3), 69I-7IO.

C o n r a d P. 1985. The meaning of medications: another look at compliance. Social Science \& Medicine $20(\mathrm{I}), 29-37$.

Coulter A., Parsons S., A skham J. 2008. Where are patients in decision-making about their own care? Copenhagen.

$\mathrm{D}$ a h $\mathrm{l}$ V.H. 2007. The methadone game: control strategies and responses. In J. Fountain and D. J. Korf (eds.), Drugs in society: European perspectives. Oxford, IO2-II5.

$\mathrm{Du} \mathrm{rh}$ a m D. 2000. Youth and the social imagination in Africa: Introduction to parts I and 2. Anthropological Quarterly 73 (3), II3-I2O.

European Monitoring Centre for Drugs and Drug Addiction. 20I7. Norway. Country drug report 20I7, European drug report. Luxembourg.

Fain z ang S. 20I4. Managing medicinal risks in self-medication. Drug Safety 37 (5), 333-342.

F is ch e r E. 20I4. Good life: aspiration, dignity, and the anthropology of wellbeing. Palo Alto.

Fried man J. and Alice a M. 200I. Surviving heroin: interviews with women in methadone clinics. Gainesville.

G ill V.T. 2005. Patient "demand" for medical interventions: exerting pressure for an offer in a primary care clinic visit. Research on Language and Social Interaction 38 (4), 45I-479.

Gjersing L., Waal H., Røislien J., Gossop M., Clausen T. 20Ir. Variations in treatment organisation, practices and outcomes within the Norwegian opioid maintenance treatment programme. Norsk epidemiologi 2I (I), II3-II8.

Gubrium J.F., Andreassen T. A., Solvang P. 2016. Reimagining the human service relationship. New York.

Gurmankin A. D., B aron J., Hershey J., Ubel P.A. 2002. The role of physicians' recommendations in medical treatment decisions. Medical Decision Making 22 (3), 262-27I.

$\mathrm{H}$ a ck ing I. 1985. Making up people. In T. L. Heller, M. Sosna, D. E. Wellbery (eds.), Reconstructing individualism. Stanford, I6I-I7I.

$\mathrm{Harr}$ is M. and $\mathrm{Rhodes}$ T. 20I3. Methadone diversion as a protective strategy: the harm reduction potential of 'generous constraints'. International Journal of Drug Policy 24 (6), 43-50.

$\mathrm{H}$ arris S. 20I5. To be free and normal: addiction, governance, and the therapeutics of buprenorphine. Medical Anthropology Quarterly 29 (4), 512-530.

Hedrich D., Alves P., Farrell M., Stöver H., Møller L., Mayet S. 20I2. The effectiveness of opioid maintenance treatment in prison settings: a systematic review. Addiction 107 (3), 50I-517.

Helsedirektoratet. 20I0. Nasjonal retningslinje for legemiddelassistert rehabilitering ved opioidavhengighet. Oslo.

He r z feld M. 1992. The social production of indifference: exploring the symbolic roots of Western bureaucracy. New York. 
Ho a C. 20II. Assembling partial perspectives: thoughts on the anthropology of bureaucracy. Political and Legal Anthropology Review 34 (I), 8I-94.

Hog get t P. 200I. Agency, rationality and social policy. Journal of Social Policy 30, 37-56.

$\mathrm{H}$ o n w a n A. 2005. Innocent and guilty. Child-soldiers as interstitial and tactical agents. In A. Honwana and F. De Boeck (eds.), Makers and breakers: children and youth in postcolonial Africa. Oxford and Dakar, 3I-52.

Hy m a n S. E. 2005. Addiction: a disease of learning and memory. American Journal of Psychiatry 162 (8), I4I4-I422.

Institute of Medicine. 200I. Crossing the quality chasm: A new health system for the $2 I^{\text {st }}$ Century. Washington.

Karnieli-Miller O. and Eisikovits Z. 2009. Physician as partner or salesman? Shared decision-making in real-time encounters. Social Science \& Medicine 69 (I), I-8.

$\mathrm{Ki}$ r m a y e $\mathrm{L}$ L. J. 1992. The body's insistence on meaning: metaphor as presentation and representation in illness experience. Medical Anthropology Quarterly 6 (4), 323-346.

$\mathrm{K}$ le in $\mathrm{m}$ a $\mathrm{n}$ A. 1980. Patients and healers in the context of culture: an exploration of the borderland between anthropology, medicine, and psychiatry. Berkeley.

Klocker N. 2007. An example of 'thin' agency: child domestic workers in Tanzania. In R. Panelli, S. Punch and E. Robson (eds.), Global perspectives on rural childhood and youth: young rural lives. New York, 83-94.

Ko en ig C. J. 20II. Patient resistance as agency in treatment decisions. Social Science \& Medicine 72 (7), IIO5-III4.

Lavie S., Narayan K., Rosald o R. 1993. Creativity/anthropology. Ithaca.

L e a ch E. 1977. Custom, law, and terrorist violence. Edinburgh.

L u c a s S. D. 2016. The primacy of narrative agency: a feminist theory of the self. Sydney.

L u c a s S. D. 20I7. The primacy of narrative agency: re-reading Seyla Benhabib on narrativity. Feminist Theory, First Published August 23, 2017.

Mahmood S. 20oI. Feminist theory, embodiment, and the docile agent: some reflections on the Egyptian Islamic revival. Cultural Anthropology I6 (2), 202-236.

Marcu s G. E. 200o. Introduction. In G. E. Marcus (ed.), Para-sites: a casebook against cynical reason. Chicago, I-I5.

Mat t ingly C. 2009. Senses of ending: self, body, and narrative. In U. J. Jensen and C. Mattingly (eds.), Narrative, self and social practice. Århus, 245-269.

$\mathrm{Mj}$ åla nd K. 20I5. The paradox of control: An ethnographic analysis of opiate maintenance treatment in a Norwegian prison. International Journal of Drug Policy 26 (8), 78I-789.

M o o r e D. 2008. Erasing pleasure from public discourse on illicit drugs: on the creation and reproduction of an absence. The International Journal on Drug Policy I9 (5), 353-358.

Petryna A. 2002. Life exposed: biological citizens after Chernobyl. Princeton.

$\mathrm{R}$ a p port N. and Overing J. 2000. Social and cultural anthropology: the key concepts. London.

Riksheim M., Gossop M., Clausen T. 20I4. From methadone to buprenorphine: Changes during a Io year period within a national opioid maintenance treatment programme. Journal of Substance Abuse Treatment 46 (3), 29I-294.

Skeie I., Brekke M., Gossop M., Lindbaek M., Reinertsen E., Thoresen M., Wa al H. 20II. Changes in somatic disease incidents during opioid maintenance treatment: results from a Norwegian cohort study. BMJ Open I (I), doi: Io.II36/bmjopen-20II-000I30.

$S$ tivers T. 2005. Parent resistance to physicians' treatment recommendations: one resource for initiating a negotiation of the treatment decision. Health Communication $\mathrm{I} 8$ (I), 4I-74. 
Strauss A.L., Schatzman L., Ehrlich D., Bucher R., Sabshin M. 1963. The hospital and its negotiated order. In E. Freidson (ed.), The hospital in modern society. New York, I47-169.

Trostle J.A. 1988. Medical compliance as an ideology. Social Science \& Medicine 27 (12), I299-1308.

Wa al H., B ussesund K., Cla usen T., Lillevold P.H., Ske i e I. 20I8. LAR 20 år. Status, vurderinger og perspektiver. Statusrapport 2017. SERAF Rapport 3/2018. Oslo.

Webster A., Douglas C., Lew is G. 2009. Making sense of medicines: 'lay pharmacology' and narratives of safety and efficacy. Science as Culture I8 (2), 233-247.

World Health Organization. 1992. International statistical classification of diseases and related health problems. Geneva.

\section{Author's address:}

Aleksandra Bartoszko PhD

VID Specialized University, Faculty of Social Studies

Postboks I84 Vinderen

0319 Oslo, NORWAY

e-mail: Aleksandra.Bartoszko@vid.no

ORCID: 0000-0002-2919-545X 
